\author{
Ewa Gumul \\ Uniwersytet Śląski \\ ewa.gumul@us.edu.pl
}

\title{
O METODZIE PROTOKOLÓW RETROSPEKTYWNYCH W BADANIACH NAD TŁUMACZENIEM SYMULTANICZNYM
}

DOI: http://dx.doi.org/10.12775/RP.2019.008

\begin{abstract}
Zarys treści: Celem artykułu jest omówienie zastosowania metody protokołów retrospektywnych w badaniach nad tłumaczeniem symultanicznym. Autorka omawia cechy tej metody w kontekście innych metod procesualnych. Przedstawia także zróżnicowane procedury retrospektywne stosowane w przeprowadzonych dotychczas badaniach translatorycznych. Ponadto celem artykułu jest omówienie ograniczeń tej metody oraz sposobów na to, by je zniwelować. Materiał egzemplifikacyjny przedstawiony w artykule pochodzi z badań własnych autorki.
\end{abstract}

Słowa kluczowe: tłumaczenie symultaniczne, protokoły retrospektywne, metody badawcze, proces przekładu

\section{Badania nad procesem przekładu}

W ostatnich dwóch dekadach widoczny jest wyraźny wzrost zainteresowania badaniami nad procesem przekładu. W specjalnym wydaniu czasopisma Monti Muñoz Martín (2014a, 2014b) mówi wręcz o „eksplozji” badań nad tym aspektem przekładu. Według jego analizy, tylko w latach 2006-2013 opublikowano 317 prac badających proces przekładu. Należy podkreślić, że zestawienie to obejmuje jedynie prace opublikowane w języku angielskim i nie uwzględnia prac doktorskich. Gdy weźmiemy pod uwagę również prace opublikowane w innych językach (np. prace Piotrowskiej (2006, 2007), Kubiaka (2009) i Płużyczki $(2013,2015)$ na gruncie polskim, jak również publikacje grupy PACTE w języku hiszpańskim - m.in. Hurtado Albir et al. 2002) 
oraz liczne artykuły i monografie opublikowane w ostatnich latach, wyraźnie widać, że skala badań nad procesem przekładu jest imponująca.

Metody badawcze używane w tego rodzaju badaniach to protokoły głośnego myślenia, protokoły retrospektywne, wywiady retrospektywne, ankiety, analiza zrzutów ekranu, keylogging oraz okulografia. Pierwsze cztery to metody subiektywne, polegające wyłącznie na relacjach badanych osób. Mają one też najdłuższą tradycję w badaniach translatorycznych. Protokoły głośnego myślenia, polegające na jednoczesnej werbalizacji procesów myślowych podczas tłumaczenia, kiedy to tłumacz przyjmuje rolę „komentatora procesu werbalizującego swoje myśli na każdym etapie aktu przekładania" (Piotrowska 2000: 163), są stosowane w badaniach nad przekładem pisemnym przez szereg badaczy od lat 80. XX wieku (np. Tirkkonen-Condit 1992; Jääskeläinen i Tirkkonen-Condit 1991; Piotrowska 2002; Englund Dimitrova 2005; Hjort-Pedersen i Faber 2010). Z kolei protokoły retrospektywne, o których będzie mowa w niniejszej pracy, to wariant stosowany głównie w przekładzie ustnym ze względu na niemożność jednoczesnej werbalizacji procesów myślowych podczas tłumaczenia ustnego. Do subiektywnych metod procesualnych można także do pewnego stopnia zaliczyć ankiety (m.in. Dybiec-Gajer 2013). Oprócz metod subiektywnych, dzięki gwałtownemu rozwojowi technologii w ostatnich dekadach badacze przekładu mają także do dyspozycji metody wymagające specjalistycznego sprzętu czy oprogramowania, takie jak keylogging, czyli rejestrowanie ruchów na klawiaturze i ruchów kursora (m.in. O’Brien 2007; Whyatt et al. 2016; Hvelplund i Dragsted 2018), analizę zrzutów ekranu (Shreve et al. 2014) oraz okulografię, która pozwala na śledzenie ruchów gałek ocznych podczas tłumaczenia (m.in. O’Brien 2008; Chmiel i Mazur 2013; Płużyczka 2013, 2015).

Metody te przyczyniły się w znacznym stopniu do rozwoju translatoryki. Należy jednak pamiętać, że niestety żadna z nich nie umożliwia bezpośredniego wglądu w procesy mentalne tłumaczy (Saldanha i O’Brien 2013). Jak podkreśla Kościałkowska-Okońska (2013: 244), „nie mamy wglądu w procesy umysłowe, a ocenie poddawany jest raczej tylko rezultat tychże procesów i mechanizmów". Mimo tych ograniczeń potencjał metod procesualnych jest ogromny. Przede wszystkim, w przeciwieństwie do badań zorientowanych na produkt, pozwalają przynajmniej na częściowy wgląd w "czarną skrzynkę" tłumacza. Jak podkreśla wielu badaczy (m.in. Alves 2003; Saldanha i O’Brien 2013; Hurtado Albir et al. 2015), konieczna jest jednak triangulacja metod badawczych, która pozwala na uwiarygodnienie wyników badań. Mowa tu zarówno o łączeniu samych metod procesualnych, czego przykładem jest zastosowanie np. keyloggingu i okulografii m.in. w pracy Hvelplund i Dragsted 
(2018) czy też keyloggingu i protokołów retrospektywnych w badaniach Ferreiry (2014), jak i o triangulacji metod zorientowanych na proces $\mathrm{z}$ analizą produktu przekładu. Ta ostatnia jest wykorzystywana bardzo często w pracach badających proces przekładu, jednak jednym z najciekawszych przykładów jest opisany w pracy Rodríguez-Inéz (2017) projekt CORPRAT, w ramach którego badacze z brazylijskiego Uniwersytetu Minas Gerais łączą aż pięć metod badawczych, analizując ruchy na klawiaturze za pomocą programu Translog, protokoły głośnego myślenia oraz protokoły retrospektywne, badanie okulografem, a także sam produkt przekładu, czyli przetłumaczone teksty.

\section{Protokoły retrospektywne}

Ze względu na specyfikę tłumaczenia symultanicznego badanie tej formy przekładu jest możliwe jedynie za pomocą retrospekcji: protokołów retrospektywnych, wywiadów retrospektywnych lub ewentualnie ankiet, które również mogą być pewną formą retrospekcji. W metodzie protokołów retrospektywnych tłumacz po ukończeniu zadania (tłumaczenia) stara się przywołać z pamięci i zwerbalizować świadome procesy kognitywne, które zachodziły w trakcie przekładu. W zależności od procedury badawczej przewidzianej w danym badaniu tłumacz może zostać poproszony o raporty werbalne dotyczące wszystkiego, o czym myślał w trakcie tłumaczenia, bądź też jednego wybranego aspektu.

Poniższy przykład, pochodzący z korpusu zgromadzonego na potrzeby badań własnych autorki (Gumul 2017a, 2018), pokazuje fragment protokołu retrospektywnego, na który składa się osiem segmentów (RC11 do RC19). Aby w pełni pokazać specyfikę tej metody, w przykładzie ujęto także fragment tekstu wyjściowego (ST) oraz tekstu docelowego w formie tłumaczenia symultanicznego (TT):

(1)

ST (T2): * wasz krytyk to zewnętrzny świat / i byłoby szalonym pomysłem wypowiedzieć wojnę całemu światu / albo się na świat obrażać / niestety jest to dziś dosyć popularna postawa / szczególnie wśród artystów / ileż razy słyszałem że publiczność jest głupia / rozumiem że le-
TT (P22): our critic is the person $/{ }^{* *}$ who is very important ${ }^{\mathrm{RC11}}$ to us / it's an entire world and it would be stupid to wage war on the entire world ${ }^{\mathrm{RC12}} /$ however today unfortunately it is a really popular eee behaviour particularly among artists / many times I heard that the public is stu- 
karz może powiedzieć do pacjenta jesteś głupi że palisz papierosy lub że zażywasz narkotyki / ale jak artysta może powiedzieć do widza jesteście głupi / bo moja sztuka wam się nie podoba / albo jesteście głupi bo nie rozumiecie mojej sztuki / często wasz krytyk gdy będziecie go dobrze słuchać / stanie się inspiracją waszej nowej idei / tylko krytyka może Was upewnić i pomóc w stworzeniu i realizacji waszej wizji / poprzez krytykę rozumiejcie przede wszystkim samego siebie / słuchajcie siebie najuważniej / to bardzo cichutki szept / trzeba się nauczyć go słyszeć / nie ceńcie za bardzo swoich prac i osiągnięć / i siebie samych jako artystów / pozostawcie to innym i historii / bądźcie samokrytyczni i kształćcie tę umiejętność / to wielka sztuka / wielu artystów napędza się dosyć naiwną i zgubną myślą / artysta powinien za wszelką cenę wyrażać siebie / jak to wygląda w praktyce / otóż po obudzeniu się z rana / albo po wyjściu z McDonalda / nagle doznajemy tajemniczego olśnienia / jesteśmy przekonani że oto wpadliśmy na genialną / wspaniałą / odjazdową ideę / tak tak koniecznie musimy natychmiast podzielić się tym z całym światem / to bardzo żałosna postawa / ja znam może tylko dwa wypadki w historii ostatnich kilkuset lat kiedy to się prawdopodobnie wydarzyło / wielka idea jak piorun $\mathrm{z}$ jasnego nieba przeszyła ludzki mózg / tymi szczęśliwcami byli Newton i Einstein / u reszty wyglądało to trochę inaczej / osiągnięcia wielkich twórców odkrywców / naukowców / tych którzy w istotny sposób mieli i mają wpływ na rozwój naszej cywilizacji / były i są oku- pid / I understand that a doctor can say to a patient that he or she is stupid that he or she is drinking ${ }^{\mathrm{RC} 13}$ / eee or taking drugs / but how can an artist say to the public / that he or she is stupid because they don't like the / ee the $\operatorname{art}^{\mathrm{RC} 14}$ // very often you're the person who criticizes you when you listen to him carefully will become and give you inspiration to you to new ideas // only criticism may make you sure and help you realize your ideas // through criticism / you should understand your own person / listen to yourself most with most attention / it's only a faint whisper / and one must learn to hear it // don't appreciate your work and achievements too much and don't respect yourself as artists too much / leave it to the others and history // try to criticise yourself as well / and eee improve this ability / it's a great skill // many artists are driven by the naïve and misleading thought // the artist / should at all costs express himself / in practice how-

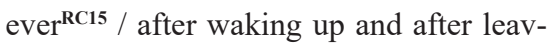
ing eee the MacDonald / we are suddenly illuminated / we are convinced that it is / the greatest ${ }^{\mathrm{RC} 16}$ idea we have ever found / yes and this idea makes us / want to share it with the whole world / it's a very pathetic behaviour // I personally know only two cases in the history ${ }^{\mathbf{R C 1 7}}$ when it actually happened / the great idea / the bolt from the sky / eee crossed the human mind / these persons ${ }^{\mathrm{RC} 18}$ were Newton and Einstein / the rest was quite different // the achievements of great artists discoverers and scientists / generally people who influence eee the development of our civilization were and still are eee related 
pione ciężką pracą której podstawową to ${ }^{\mathrm{RC} 19}$ hard work / in which the basis eee metodą działania był $\mathrm{i}$ jest eksperyment mode of working is experiment

* Oznaczenia użyte przy kodowaniu korpusu to kolejno: numer tekstu wyjściowego (do oznaczenia użyto skrótu ST od angielskiego source text): T1-T6, numer uczestniczącego w badaniu tłumacza (nazwanych participants, stąd oznaczenie P) umieszczony przy każdym tekście docelowym (TT od angielskiego target text): P01-P120, oraz numer segmentu protokołu retrospektywnego dla danego tekstu docelowego: RC + numer każdego kolejnego komentarza; w przypadku każdego tekstu docelowego numeracja zaczyna się od RC1. Użyty w kodowaniu symbol RC jest skrótem od retrospective comment.

** Ukośniki służą do oznaczania pauz. Pojedynczy (/) oznacza krótką pauzę, natomiast podwójny ukośnik (//) oznacza pauzę powyżej 2 sekund.

RC11: Dodałem, że krytyk to jest bardzo ważna osoba, chociaż nie było tego w tekście oryginalnym. Aczkolwiek nie zmienia to i nie wpływa na znaczenie całości tej wypowiedzi.

RC12: Pominąłem drugą część zdania po wypowiedzeniu wojny albo obrażaniu się na niego, ponieważ stwierdziłem, że nic nowego nie wnosi do tekstu, a trzeba już było skupić się na kolejnym fragmencie.

RC13: Jakoś wyobrażając sobie lekarza, który mówi do pacjenta pierwsze co wpadło mi na myśl to picie alkoholu zamiast palenia papierosów i tak też niestety powiedziałem, ale jak się okazuje nie miało to wpływu na znaczenie wypowiedzi, bo i to i to jest złe dla naszego zdrowia. Tak więc był to taki przykład, który można było wolno interpretować.

RC14: Wyszedłem z założenia, że jak się coś komuś nie podoba, to bardzo często jest tak, że tego nie rozumie. Dlatego pominąłem już drugą część zdania, która polegała na powtórzeniu praktycznie tych samych informacji.

RC15: Celowo pominąłem pytanie retoryczne mówcy ponieważ z doświadczenia wiem, że pytania retoryczne w języku angielskim nie bardzo funkcjonują i zazwyczaj powinno się je przekształcać w zdania twierdzące.

RC16: Wszystkie wymienione przez mówcę przymiotniki zmieniłem na jeden bardzo ogólny great i myślę, że załatwiło to całą sprawę i było szybsze niż starać się wymyślić jakieś synonimy na odjazdowy. W sumie genialny wspaniały odjazdowy znaczą wszystkie to samo.

RC17: Dokonałem uogólnienia i nie sprecyzowałem dokładnie, że chodzi o historię ostatnich kilkuset lat. W sumie kilkuset nie wiadomo dokładnie o ile chodzi więc stwierdziłem, że na przełomie historii będzie odpowiedniejszym tutaj znaczeniem.

RC18: Zamiast szczęśliwcami dodałem ludźmi ponieważ z wcześniejszego zdania wynika, że oni byli nie tylko wybranymi osobami, którym udało się tego dokonać, a więc w domyśle szczęśliwcami.

RC19: Nie mogąc wymyślić odpowiedniego synonimu na być okupionym czymś, na przykład ciężką pracą postanowiłem się skupić na ogólnym znaczeniu i powiedzieć, że są związane z ciężką pracą. 
Protokoły retrospektywne to metoda zainspirowana badaniami za pomocą protokołów głośnego myślenia w przekładzie pisemnym po raz pierwszy użytych w translatoryce w latach 80 . XX wieku i, podobnie jak protokoły głośnego myślenia (ang. TAPs), zapożyczonych z psychologii. Kluczową rolę w rozwoju tej metody badawczej w translatoryce odegrały prace psychologów Ericssona i Simona $(1980,1984)$, choć niezależnie od badań psychologicznych pewna forma retrospekcji właściwie od zawsze była obecna w translatoryce. Jak słusznie podkreśla Piotrowska (2007), protokoły werbalne można postrzegać jako kontynuację tradycji komentarzy odautorskich, od zawsze towarzyszących przekładom. Walory poznawcze tego rodzaju metatekstu dostrzegł m.in. Balcerzan (1977), który wskazywał na możliwość poznania $\mathrm{w}$ ten sposób intencji tłumacza.

Protokoły retrospektywne mają przewagę nad protokołami głośnego myślenia - nie zakłócają w żaden sposób procesu tłumaczenia (Ferreira 2014: 112), pozwalając tym samym uniknąć dodatkowego obciążenia kognitywnego w jego trakcie ${ }^{1}$. Dlatego też metoda ta jest również z powodzeniem wykorzystywana w badaniach nad tłumaczeniem pisemnym (Alves i Gonçalves 2003; Gile 2004; Englund Dimitrova i Tiselius 2009, 2014; Ferreira 2014).

Badania $\mathrm{z}$ użyciem protokołów retrospektywnych służą badaniu procesu przekładu. Zazwyczaj jednak koncentrują się na jednym wybranym aspekcie. Do tej pory badano za pomocą tej metody:

- wpływ stopnia zaawansowania i doświadczenia zawodowego tłumaczy ustnych na proces przekładu (Ivanova 1999, 2000; Vik-Tuovinen 2002),

- powody opuszczeń w tekście docelowym (Napier 2002, 2004; Gumul 2010),

- strategie tłumaczeniowe (Bartłomiejczyk 2004, 2006, 2007a),

- strategie rozumienia tekstu w tłumaczeniu symultanicznym i konsekutywnym (Díaz Galaz 2018),

- kierunkowość (Bartłomiejczyk 2006; Chang i Schallert 2007; Gumul 2017a, 2017b),

- strategiczność i powody eksplicytacji (Gumul 2006, 2008, 2017a, 2017b; Tang 2018),

${ }^{1}$ Negatywny wpływ protokołów głośnego myślenia na sam proces przekładu podkreślają m.in. Toury (1995), Hansen (2005) i Gile (1998). Pomimo zapewnień psychologów, że myślenie na głos nie wpływa na procesy myślowe, a jedynie wydłuża czas potrzebny na wykonanie zadania (Ericsson i Simon 1984: xxii), część translatologów jest zdania, że w przypadku tłumaczenia werbalizacje mają jednak znaczący wpływ zarówno na proces, jak i sam produkt przekładu (Hansen 2005: 519). 
- nieuzasadnione dodania i opuszczenia (Gumul 2010),

- wpływ ograniczeń typowych dla przekładu symultanicznego (Gumul 2012),

- wysiłek kognitywny w tłumaczeniu symultanicznym (Gumul 2018),

- wpływ różnic systemowych pomiędzy językami (Shamy i de Pedro Ricoy 2017)

- czy wreszcie zasadność i wiarygodność samej metody (Englund Dimitrova i Tiselius 2014).

\subsection{Zróżnicowane procedury retrospektywne}

Wymienione powyżej badania znacznie różnią się, jeśli chodzi o procedurę retrospektywną. Jednym z czynników różnicujących jest czas przeprowadzenia retrospekcji. Ericsson i Simon (1984) zalecali, by retrospekcja następowała bezpośrednio po tłumaczeniu (immediate retrospection), przede wszystkim ze względu na ograniczenia pamięci tłumaczy, którzy po upływie dłuższego czasu najprawdopodobniej nie będą już pamiętać powodów większości podjętych decyzji i nie będą w stanie odtworzyć swojego toku myślenia podczas powstawania tekstu docelowego. Należy jednak pamiętać, że przeprowadzenie sesji retrospektywnej bezpośrednio po tłumaczeniu możliwe jest najczęściej w badaniach eksperymentalnych lub quasi-eksperymentalnych przeprowadzonych w warunkach laboratoryjnych (Bartłomiejczyk 2004, 2006, 2007a; Gumul 2006, 2017a; Englund Dimitrova i Tiselius 2009, 2014; Tang 2018). Badania przeprowadzone w naturalnych warunkach podczas konferencji na ogół wymuszają znacznie opóźnioną sesję retrospektywną (Vik-Tuovinen 2002), która może odbyć się kilka godzin później lub nawet następnego dnia.

Zalecana przez Ericssona i Simona natychmiastowość retrospekcji odnosi się również do długości werbalizowanego podczas retrospekcji zadania. Ericsson i Simon twierdzą, że optymalne opóźnienie, które daje pełną gwarancję zapamiętania procesów kognitywnych, nie powinno być dłuższe niż 10 sekund. W badaniach z zakresu dydaktyki języków obcych Cohen i Hosenfeld (1981) terminu natychmiastowa retrospekcja (immediate retrospection) używają jedynie w odniesieniu do zadań, które nie mają więcej niż 30 sekund. Werbalizacje po dłuższych zadaniach traktują jako opóźnioną retrospekcję (delayed retrospection). Widać więc wyraźną różnicę pomiędzy użyciem tych terminów w zależności od dziedziny. Specyfika tłumaczenia właściwie wyklucza zadania tej długości, więc to, co w translatoryce nazywamy 
natychmiastową retrospekcją, biorąc pod uwagę jedynie opóźnienie czasowe od ukończenia zadania do rozpoczęcia sesji retrospektywnej, w psychologii i glottodydaktyce jest już traktowane jako opóźniona retrospekcja. W przeprowadzonych dotychczas badaniach translatorycznych z użyciem tej metody długość tekstu na ogół waha się od kilku (Englund Dimitrova i Tiselius 2014) do kilkunastu minut (Gumul 2017a) i jest uzależniona od badanego zjawiska. Celem badania Englund Dimitrovej i Tiselius było ustalenie zbieżności problemów sygnalizowanych $w$ raportach retrospektywnych z oznakami trudności uwidocznionymi w samym produkcie przekładu w formie niewypełnionych pauz i innych zakłóceń płynności wypowiedzi. Relatywnie krótki tekst o długości 9 minut był zatem w zupełności wystarczający, aby zanalizować badane zjawisko. $Z$ drugiej strony dłuższy tekst daje większe możliwości, na przykład prześledzenia sekwencji strategii ratunkowych i ich wzajemnej zależności, a także konsekwencji w stosowaniu pewnych rozwiązań, które dają obraz indywidualnego stylu tłumacza. Stąd też teksty o długości od 15 do 22 minut w badaniu Gumul (2017a), którego celem było zbadanie idiosynkrazji w użyciu eksplicytacji u tłumaczy symultanicznych. Należy jednak pamiętać, że im dłuższy czas samego zadania, tym mniejsze szanse zapamiętania wszystkich podjętych decyzji.

Próbę zachowania minimalnego opóźnienia czasowego zgodnego z postulatami Ericssona i Simona podjęli jedynie Ng i Obana (1991) i badacze z chilijskiego uniwersytetu Pontificia Universidad Católica de Valparaíso (Díaz Galaz 2018). W eksperymencie tych pierwszych tłumacze przerywali tłumaczenie po każdym zdaniu i werbalizowali podjęte decyzje. Trudno jednak w tym przypadku mówić o ukończonym zadaniu, jako że tłumacz symultaniczny nie przetwarza $w$ ten sposób tekstu. Ponadto metoda ta wydaje się niezwykle inwazyjna - proces retrospekcji z pewnością działa rozpraszająco na tłumacza, któremu trudno w tych warunkach zachować spójność tekstu. $\mathrm{W}$ rezultacie tak przetłumaczony tekst docelowy przybiera formę pojedynczych zdań, każde z nich tworzące mikrotekst. Z kolei w badaniu Díaz Galaz (2018) tłumacze mieli za zadanie przetłumaczyć dziewięć 90-sekundowych tekstów, z których każdy kończył się sesją retrospektywną w formie wywiadu. To rozwiązanie wydaje się bardziej zasadne niż przerywanie tłumaczenia po każdym zdaniu. W dalszym ciągu nie przypomina jednak prawdziwego zlecenia tłumaczeniowego i nie daje możliwości prześledzenia pewnych procesów kognitywnych i zjawisk tekstowych, których zbadanie wymaga dłuższego segmentu tekstu.

Badacze stosujący metodę protokołów retrospektywnych używają różnych bodźców, by uruchomić pamięć tłumaczy. Może to być transkrypcja 
tekstu wyjściowego (np. Ivanova 1999; Englund Dimitrova i Tiselius 2009, 2014) lub nagranie tekstu docelowego (np. Bartłomiejczyk 2004, 2006; Gumul 2006, 2017a; Díaz Galaz 2018). Natomiast Vik-Tuovinen (2002) włączyła do badania oba bodźce. Każde z tych rozwiązań ma swoje minusy. Łączenie transkrypcji i nagrania tekstu docelowego stwarza nadmiar bodźców i może działać rozpraszająco na badanych tłumaczy, podczas gdy sama transkrypcja tekstu wyjściowego może okazać się bodźcem niewystarczającym, słabo stymulującym pamięć. $Z$ kolei nagrania tekstu docelowego mogą prowokować komentarze, które są obserwacjami poczynionymi post factum i nie odzwierciedlają decyzji świadomie podjętych podczas procesu tłumaczenia, czego przykładem jest poniższy komentarz:

\section{(2)}

P08/T2/RC13: ${ }^{2}$ Byłam święcie przekonana, że mówię you're wasting your time, a powiedziałam you're wasting your money i teraz dopiero usłyszałam, że wypowiedziałam coś zupełnie innego. Nie zdarzyło mi się to nigdy wcześniej podczas tłumaczenia. Wiadomo, że zdarzają się takie jakieś przejęzyczenia, coś się źle wypowie, ale teraz jestem zaskoczona, że można powiedzieć coś zupełnie innego niż to, o czym się myśli w tym momencie. To pewnie dlatego, że miałam problem ze słowem pochwała, znowu się skoncentrowałam na słowach i postanowiłam $\mathrm{z}$ tego wybrnąc, używając może bardziej takiego górnolotnego określenia honoured (...).

Bez względu na rodzaj zastosowanego bodźca, każdy z nich niesie za sobą ryzyko wystąpienia fałszywych wspomnień (ang. installing false memories). Mechanizm ich występowania jest związany $\mathrm{z}$ funkcjonowaniem pamięci generatywnej, która uruchamia skrypt danej sytuacji (Olszewska 2007). $\mathrm{W}$ ten sposób tłumaczowi może wydawać się, że pamięta zachowania, które są typowe dla pewnych sytuacji tłumaczeniowych, a które tym razem wcale nie nastąpiły.

Kolejnym czynnikiem różnicującym przeprowadzone za pomocą protokołów retrospektywnych badania jest stopień ingerencji badacza podczas sesji retrospektywnej. W wielu pracach na temat metodologii badań przekładu (m.in. Kalina 1998) podkreśla się, że udział badacza w samej retrospekcji

${ }^{2}$ Oznaczenia użyte przy kodowaniu segmentów protokołów retrospektywnych to kolejno: numer uczestniczącego w badaniu tłumacza (P01-P120), numer tekstu wyjściowego (T1-T6) oraz numer segmentu protokołu retrospektywnego dla danego tekstu docelowego (RC + numer każdego kolejnego komentarza; w przypadku każdego tekstu docelowego numeracja zaczyna się od RC1). 
powinien być minimalny i ograniczać się do wydania niezbędnych instrukcji przed rozpoczęciem sesji, aby nie zakłócać procesu retrospekcji i nie wpływać na werbalizacje tłumaczy ${ }^{3}$. W praktyce jednak podejścia badaczy znacznie się różnią. W przypadku badań Bartłomiejczyk (2004, 2006) i Gumul (2006, 2017a, 2017b) badaczki nie ingerowały w żaden sposób w proces retrospekcji. Każdy z tłumaczy słuchał w kabinie własnego tłumaczenia, dokonując jednocześnie retrospekcji. Przykładowo, w badaniu Gumul (2017a) tłumacze otrzymali ogólne instrukcje oraz informacje na temat tekstu przed tłumaczeniem (przykład 2 poniżej) i bardziej szczegółowe instrukcje dotyczące formy i treści protokołów retrospektywnych bezpośrednio przed rozpoczęciem sesji retrospektywnej (przykład 3):

(3)

Tekst, który mają Państwo przetłumaczyć, to wykład inauguracyjny wygłoszony przez Zbigniewa Rybczyńskiego ${ }^{4}$ na otwarcie roku akademickiego 2010/2011 w Auli Leopoldina Uniwersytetu Wrocławskiego 11 października 2010 roku. Tekst ma około 20 minut. Po skończonym tłumaczeniu poproszę Państwa o przesłuchanie swojego tłumaczenia i skomentowanie go. Szczegółowe instrukcje otrzymają Państwo po zakończeniu tłumaczenia.

(4)

Za chwilę wysłuchają Państwo swoich tłumaczeń. Proszę o komentarze dotyczące wszystkich świadomie podjętych decyzji w trakcie tłumaczenia. Komentarze NIE powinny dotyczyć jakości tłumaczenia, a wyłącznie podjętych decyzji i powodów podjęcia takich decyzji. Ilekroć będą Państwo chcieli skomentować swoje tłumaczenie, proszę zatrzymać plik z tłumaczeniem i wygłosić komentarz. Proszę oznaczyć komentowany fragment tekstu w tabeli, zapisując dwa lub trzy ostatnie słowa fragmentu (aby można było ustalić, czego dotyczy komentarz). Nie ma znaczenia język, w jakim będą Państwo robić komentarze. Może to być polski, angielski lub mieszanka obu języków. Proszę nie przejmować się formą komentarzy i ich poprawnością składniową. Powinny to być spontaniczne komentarze. Nie ma limitu ilości komentarzy ani ich długości. Proszę mówić tylko o świadomie podjętych decyzjach, czyli

${ }^{3}$ Warto zaznaczyć, że nieco inne podejście prezentują badacze w dziedzinie glottodydaktyki. Rola badacza jest zdecydowanie bardziej aktywna: jego zadaniem jest towarzyszyć badanemu i zachęcać go do werbalizacji, choć istotne jest również, aby nie przeszkadzać osobie dokonującej introspekcji (Witkowska 2010: 149).

${ }^{4}$ W zależności od badanej grupy tłumaczy część instrukcji dotycząca tekstu wyjściowego ulegała zmianie. W badaniu użyto w sumie trzech zestawów tekstów (na każdy zestaw składał się jeden tekst $\mathrm{w}$ języku polskim $\mathrm{i}$ jeden $\mathrm{w}$ języku angielskim), $\mathrm{z}$ których każdy został przetłumaczony przez 40 tłumaczy. 
tylko o tym, o czym myśleli Państwo podczas tłumaczenia. Proszę nie wymyślać komentarzy po fakcie na podstawie nagrania własnego tłumaczenia.

Po drugiej stronie spektrum ingerencji badacza w proces retrospekcji są badania $\mathrm{w}$ formie wywiadów retrospektywnych. Ta forma retrospekcji może być jedyną metodą (np. Díaz Galaz 2018), jednak najczęściej badacze stosują ją jako narzędzie dodatkowe, niejako uzupełniające samodzielną retrospekcję tłumaczy. Przykładem są badania Tang (2018), Napier (2002) i Ivanovej (2000). Tang (2018) prosiła tłumaczy o podanie powodów eksplicytacji, wskazując na segmenty tekstu, w których badana osoba wyraziła się bardziej eksplicytnie niż to było w oryginale. Wydaje się jednak, że taka procedura niesie za sobą zwiększone ryzyko wystąpienia fałszywych wspomnień. Może też sugerować badanym odpowiedzi. W moim odczuciu tłumacz może czuć się zobligowany, by wyjaśnić powody w rzeczywistości odruchowego doboru leksykalnego czy składniowego, co w przypadku eksplicytacji może dać fałszywy obraz tego zjawiska.

\subsection{Minusy metody protokołów retrospektywnych}

Protokoły retrospektywne, podobnie jak inne introspektywne metody badawcze, są obarczone pewnym ryzykiem uzyskania zafałszowanych wyników. Przede wszystkim należy pamiętać, że jest to subiektywna metoda badawcza. Nie mamy wglądu w procesy umysłowe tłumaczy i jesteśmy zmuszeni polegać jedynie na ich relacjach, które z różnych przyczyn nie zawsze są w pełni obiektywne. Świadomi oczekiwań wobec tłumaczy oraz kryteriów oceny jakości przekładu, tłumacze do pewnego stopnia mogą opisywać proces zgodnie z tym, jak chcieliby, by był widziany, a nie jaki w rzeczywistości był.

Kolejny czynnik to ograniczenie pamięci. W przeciwieństwie do protokołów głośnego myślenia, gdzie tłumacz korzysta z pamięci krótkotrwałej i roboczej, w protokołach retrospektywnych badany musi sięgnąc do zasobów pamięci długoterminowej i najprawdopodobniej w chwili werbalizacji nie pamięta już wszystkich podjętych decyzji. Jak już wspomniałam wcześniej, jedynie natychmiastowa retrospekcja po zadaniu, które trwa nie dłużej niż 10-30 sekund, daje gwarancje zapamiętania świadomych procesów kognitywnych. Należy jednak wziąć pod uwagę, że fakt zapamiętania procesów myślowych nie oznacza, że zostaną one zwerbalizowane podczas retrospekcji. $\mathrm{Z}$ tym wiąże się kolejne ograniczenie tej metody, jakim jest brak nawyku werbalizacji własnych myśli. Dla większości badanych jest to czynność nienaturalna (Witkowska 2010: 150). 
Prawdopodobnie właśnie ten czynnik w większym stopniu niż ograniczenia pamięci jest przyczyną bardzo skąpych, lakonicznych protokołów retrospektywnych niektórych tłumaczy. Warto też pamiętać, że wraz z nabytym doświadczeniem zawodowym u tłumaczy rośnie stopień zautomatyzowania strategii tłumaczeniowych (Barłłomiejczyk 2006). Można się zatem spodziewać, że werbalizacje profesjonalnych tłumaczy, u których część procesów jest już w pełni zautomatyzowana poprzez długoletnią praktykę, będą mniej obfite niż w przypadku studentów tłumaczenia, bardziej świadomie poszukujących rozwiązania napotkanych problemów, z którymi niejednokrotnie konfrontują się po raz pierwszy. Decydujący wpływ na obszerność protokołów retrospektywnych mają z pewnością także cechy osobowości badanych. Metoda ta wymaga od tłumacza dużej otwartości, jako że niejednokrotnie wiąże się z przyznaniem się do błędu lub do użycia kontrowersyjnego rozwiązania.

Znaczne różnice $\mathrm{w}$ sposobach werbalizacji są widoczne zwłaszcza w badaniach opartych na obszernych korpusach danych (Gumul 2017a), w których lakoniczne, fragmentaryczne komentarze części badanych kontrastują z obfitymi werbalizacjami innych tłumaczy biorących udział w tym samym eksperymencie, niejednokrotnie dorównującymi pod względem objętości tekstom docelowym. W materiale retrospektywnym zebranym na potrzeby analizy eksplicytacji w przekładzie symultanicznym obejmującym protokoły retrospektywne 120 studentów specjalności tłumaczeniowej liczba komentarzy retrospektywnych waha się pomiędzy 3 a 82, a ich objętość wynosi od 68 do 4048 słów dla danego tekstu przy łącznej liczbie 5005 komentarzy w całym korpusie. Te znaczne rozbieżności w stylach werbalizacji widać w poniższym zestawieniu fragmentów protokołów retrospektywnych dwóch uczestników badania. Lakoniczne komentarze pierwszego tłumacza (P01) kontrastują z obszernymi wyjaśnieniami drugiej osoby (P08). Komentarze dotyczą tłumaczenia tego samego fragmentu tekstu: 


\begin{tabular}{|c|c|c|}
\hline & & 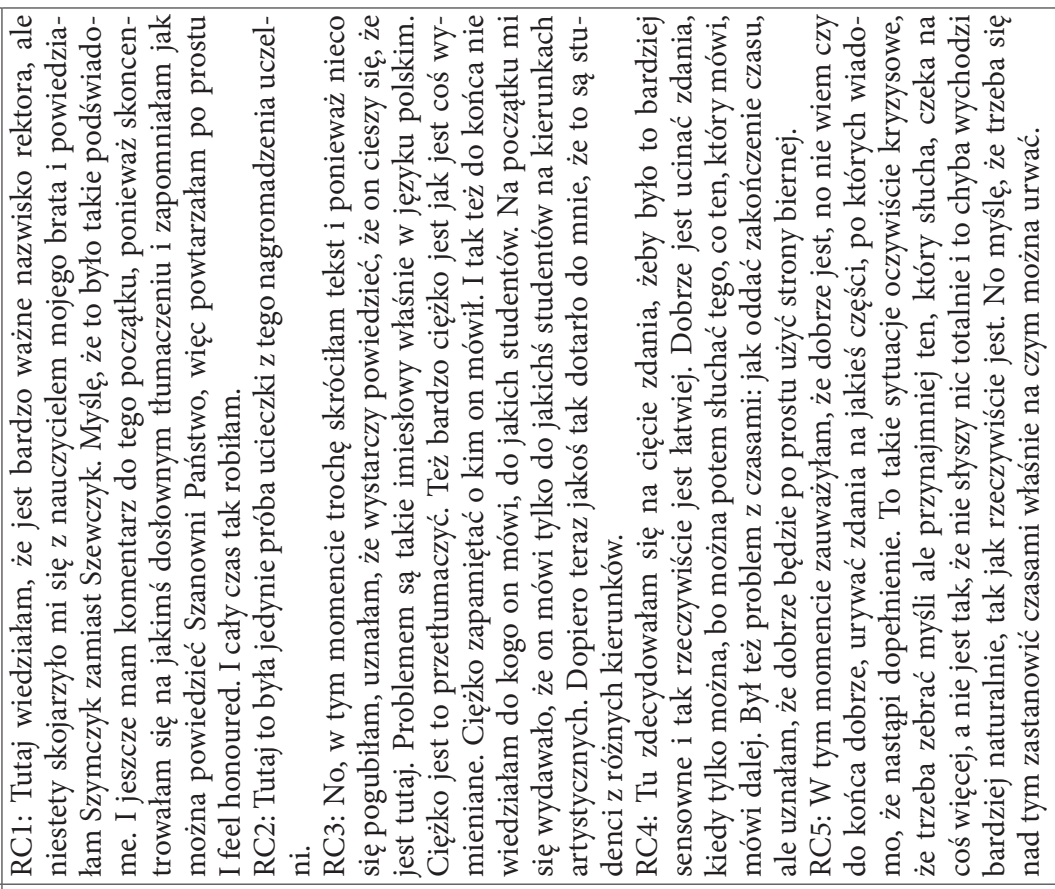 \\
\hline & $\stackrel{N}{\tilde{D}}$ &  \\
\hline & 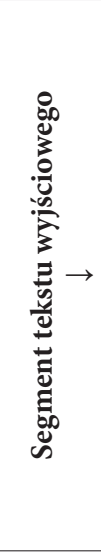 & 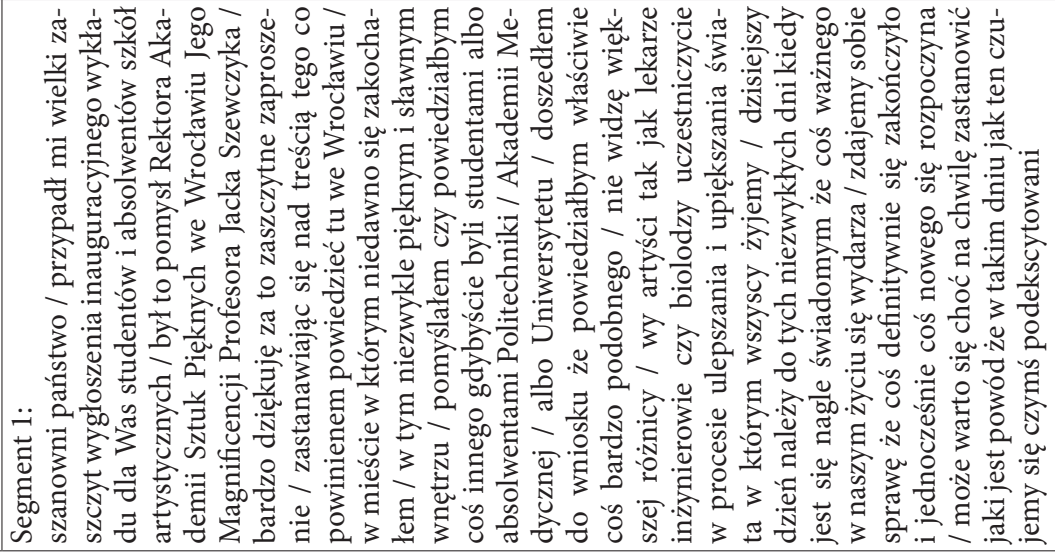 \\
\hline
\end{tabular}




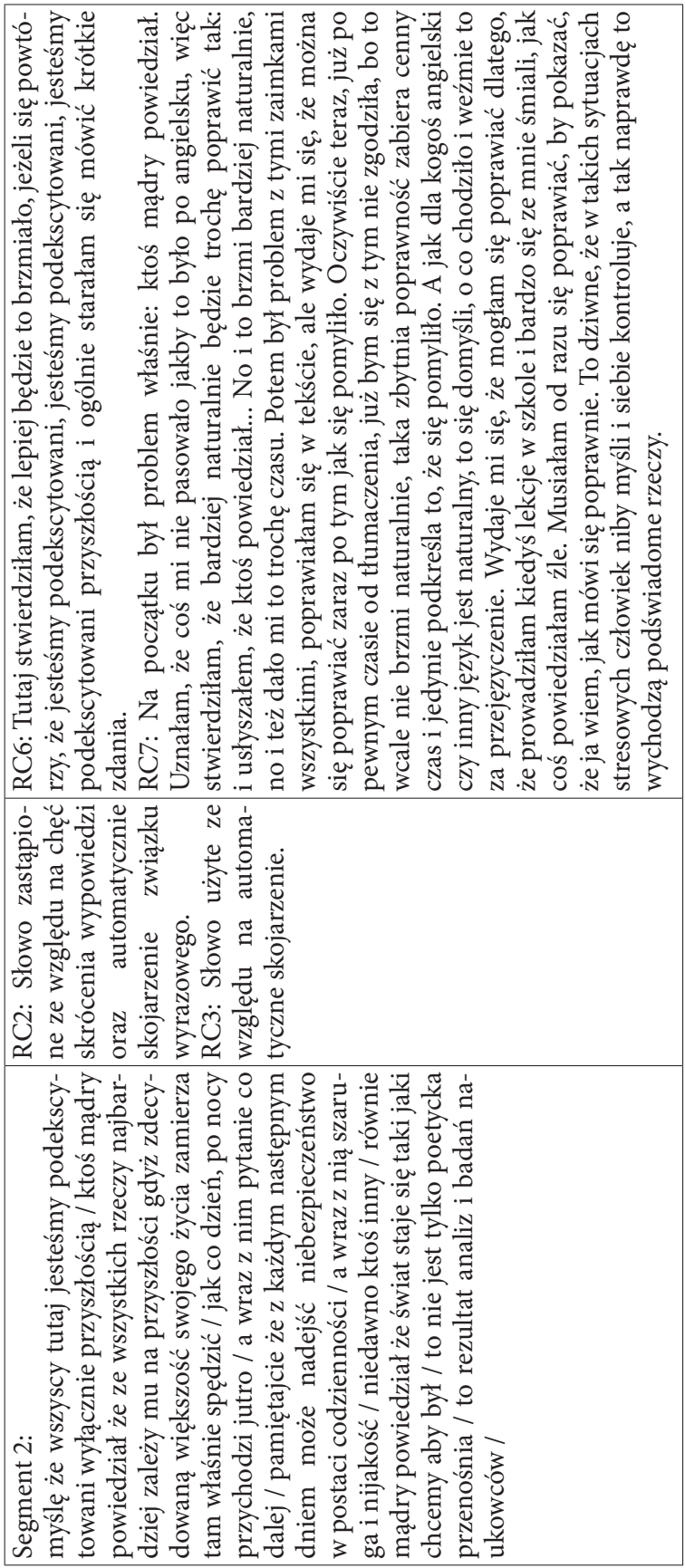


Zacytowane powyżej segmenty protokołów uwidaczniają też inny mankament tej metody, jakim jest niska selektywność komentarzy. Pomimo precyzyjnych instrukcji, by ograniczyć się do werbalizacji tylko tych procesów myślowych, które zachodziły podczas tłumaczenia, jak widać, komentarze zawierają wszelkiego rodzaju spostrzeżenia, w tym przypadku w większości nieretrospektywne. Niska selektywność komentarzy wydaje się naturalnym zjawiskiem, jako że większość badaczy dostrzega podobne tendencje w zgromadzonym przez siebie materiale. Bartłomiejczyk (2006) podaje, że tylko połowa z zebranych przez nią komentarzy retrospektywnych spełnia warunki takiego komentarza, podczas gdy w badaniach Gumul (2017a) 21,5\% (1072 z 5005) komentarzy zostało sklasyfikowanych jako ewidentnie nieretrospektywne. Jak podkreśla Hansen (2005: 519), raporty werbalne tłumaczy to nieuchronnie zbiór refleksji, uzasadnień, usprawiedliwień, wyjaśnień, emocji, wspomnień i wcześniejszych doświadczeń. Samym badanym trudno jest oddzielić to, o czym myśleli podczas tłumaczenia, od refleksji, do jakich skłoniło ich wysłuchanie własnego tłumaczenia czy też do jakich skłoniły ich inne przeżyte wcześniej sytuacje tłumaczeniowe, co może spowodować wystąpienie fałszywych wspomnień.

Jednym z powodów niskiej selektywności komentarzy może być także negatywny wpływ bodźca. Stosowane bodźce mogą zatrzeć różnicę pomiędzy tym, co realnie tłumacz pamięta, a wnioskami, do jakich doszedł, słuchając nagrania własnego tłumaczenia czy też czytając transkrypcję tekstu oryginalnego. Część komentarzy retrospektywnych jest sprowokowana samym produktem przekładu, zatem pewien odsetek komentarzy to nieuchronnie refleksje poczynione post factum. Dowodem na to są protokoły retrospektywne, w których tłumacze przyznają się do nieświadomych, odruchowych decyzji. Komentują $\mathrm{w}$ ten sposób rozwiązania, z których zdali sobie sprawę dopiero pod wpływem bodźca, co ilustruje poniższy przykład:

(5)

P107/T5/RC6: Dodałem słowa. Dodałem po prostu coś czego nie ma w oryginalnym tekście. Szczerze mówiąc nie wiem dlaczego.

Należy jednak zaznaczyć, że taki materiał również dostarcza interesujących informacji. W pewnych sytuacjach komentarze uznane za nieistotne (poczynione post factum, w których tłumacze przyznają się do nieświadomych, odruchowych decyzji) mogą okazać się cennym źródłem wiedzy. W przypadku moich badań liczne komentarze uznane za nieistotne, jako że nie opisywały decyzji świadomie podjętych podczas procesu tłumaczenia, 
potwierdziły hipotezę zakładającą nieświadomy, odruchowy charakter eksplicytacji $\mathrm{w}$ tłumaczeniu symultanicznym. Wielu tłumaczy komentowało nieświadome przypadki eksplicytacji, z których zdali sobie sprawę, dopiero słuchając własnego tłumaczenia:

(6)

P75/T2/RC12: Firstly dodałam od siebie, mimo że w ogóle nie ma tego w oryginale. Zrobiłam to nieświadomie. Być może dlatego, że pasowało do kontekstu.

Problemowi niskiej selektywności komentarzy można przynajmniej częściowo zaradzić, stosując odpowiedni system kodowania segmentów protokołów retrospektywnych, dzięki czemu już na etapie wstępnej analizy można wyeliminować komentarze niespełniające kryteriów zadania. Niejednokrotnie treść komentarzy wyraźnie wskazuje na to, że nie są to komentarze retrospektywne odzwierciedlające tok myślenia tłumacza podczas procesu przekładu, tak jak to było w powyższych przykładach (5 i 6 ).

Kolejny czynnik, który potencjalnie może zafałszować wyniki badań, to chęć pomocy badaczowi ze strony badanych osób. Ze względu na solidarność zawodową (znakomita większość badaczy przekładu ustnego to praktykujący tłumacze) bądź relację student-wykładowca badani mogą w pewnych przypadkach werbalizować rozwiązania tłumaczeniowe, których w ich odczuciu spodziewa się badacz. Aby ograniczyć ryzyko takiego zachowania, zaleca się nieinformowanie badanych o celu badania i posługiwanie się tzw. instrukcjami maskującymi (zob. także Brzeziński i Toeplitz-Winiewska 2015). Zatem jeśli badanie dotyczy eksplicytacji, zamiast poprosić tłumaczy o skomentowanie wszystkich przypadków amplifikacji tekstowej i konkretyzacji jako dwóch operacji tekstowych, które potencjalnie mogą prowadzić do eksplicytacji, lepiej poinstruować badanych, aby opisali w trakcie sesji retrospektywnej wszystkie świadomie podjęte decyzje i wskazali powody tych decyzji. W ten sposób nie sugerujemy respondentom treści komentarzy i nie prowokujemy nienaturalnych dla nich zachowań eksplicytacyjnych. Podejście takie jest uzasadnione, tym bardziej że w przeciwieństwie do niektórych badań eksperymentalnych z dziedziny psychologii, gdzie posługiwanie się instrukcjami maskującymi budzi kontrowersje natury etycznej (Brzeziński i Toeplitz-Winiewska 2015: 158), w przypadku przekładu w żaden sposób nie wiąże się ono z narażaniem badanych osób.

Niektóre z tych czynników można zminimalizować, odpowiednio projektując badanie. Dobór bodźca stymulującego pamięć, dobrane do potrzeb badania instrukcje, odpowiednie kodowanie segmentów protokołów retro- 
spektywnych oraz unikanie nadmiernej ingerencji badacza w proces retrospekcji pozwalają przynajmniej częściowo uniknąć uzyskania zafałszowanych wyników.

W stosowaniu metody protokołów retrospektywnych $\mathrm{w}$ badaniach translatologicznych przede wszystkim kluczowa jest triangulacja metod. Przekład ustny daje jednak ograniczone możliwości łączenia tej metody $\mathrm{z}$ innymi metodami procesualnymi. Pozostaje zatem triangulacja w oparciu o produkt przekładu. Rozwiązanie takie jest w mniejszym stopniu konieczne w badaniach, którym celem jest na przykład analiza refleksyjności tłumaczy czy też ich percepcji jakości własnego przekładu (Bartłomiejczyk 2007b). Takie rozwiązanie jest jednak konieczne w przypadku badań, których celem jest, powiedzmy, analiza zjawisk tekstowych (Gumul 2006, 2017a). Wówczas konfrontacja werbalizacji z faktycznym użyciem danej transformacji tekstowej jest nieodzowna.

\section{Podsumowanie}

Niewątpliwie protokoły retrospektywne są metodą niedoskonałą, obarczoną dość dużym ryzykiem zafałszowania wyników badań. Jednak pomimo swych oczywistych niedoskonałości przy obecnym stanie wiedzy i rozwoju technologicznego są jednocześnie jedyną metodą, by uzyskać choć częściowy wgląd w „czarną skrzynkę" tłumaczy symultanicznych i poznać ich motywacje w stosowaniu rozwiązań tłumaczeniowych. Jak pisze Cronin:

Protokoły werbalne są przekonujące, gdyż (pomimo wszelkich niedoskonałości) dostarczają sposobu na poznanie tego, co dzieje się w umyśle tłumacza i pozwalają nam formułować - jakkolwiek ostrożnie - rzetelny i wiarygodny psychologicznie opis aktu tłumaczenia (Cronin 2005: 251, cyt. za: Piotrowska 2007: 82).

Warto także pamiętać o dodatkowych korzyściach tej metody, będących niejako jej efektem ubocznym. Wielu tłumaczy biorących udział w moich badaniach (Gumul 2006, 2017a) uznało retrospekcję za przydatne ćwiczenie. Można zatem mówić o wpływie tej metody na samego tłumacza. Z relacji badanych wynika, że metoda ta często sprawia, że tłumacze zaczynają inaczej postrzegać proces przekładu. Można zatem przyjąć, że stosowanie metod introspektywnych $\mathrm{w}$ translatoryce nie tylko ułatwia badaczowi zrozumienie decyzji podjętych przez tłumacza, ale też pozwala samemu tłumaczowi inaczej spojrzeć na własne tłumaczenie. 


\section{Literatura}

Alves F. (red.), 2003, Triangulating Translation, Amsterdam-Philadelphia.

Alves F., Gonçalves J. L., 2003, A relevance theory approach to the investigation of inferential processes in translation, [w:] Triangulating translation: perspectives in process oriented research, F. Alves (red.), Amsterdam-Philadelphia, s. 11-34.

Balcerzan E., 1977, Pisarze polscy o sztuce przekładu. Antologia 1440-1974, Poznań.

Bartłomiejczyk M., 2004, Strategies of Simultaneous Interpreting from English into Polish and from Polish into English, niepublikowana praca doktorska, Katowice: Uniwersytet Śląski.

Bartłomiejczyk M., 2006, Strategies of simultaneous interpreting and directionality, „Interpreting”, 8(2), s. 149-174.

Bartłomiejczyk M., 2007a, Introspective methods in conference interpreting research, [w:] Challenging Tasks for Psycholinguistics in the New Century. Proceedings of the 7th Congress of International Society of Applied Psycholinguistics (CD), J. Arabski (red.), Katowice.

Bartłomiejczyk M., 2007b, Interpreting quality as perceived by trainee interpreters: Self-evaluation, „The Interpreter and Translator Trainer”, 1(2), s. 247-267.

Brzeziński J. M., Toeplitz-Winiewska M., 2015, Etyczne problemy działalności praktycznej, edukacyjnej i naukowej psychologa, [w:] Psychologia akademicka, J. Strelau, D. Doliński (red.), Gdańsk, s. 137-174.

Chang C., Schallert D., 2007. The impact of directionality on Chinese/English simultaneous interpreting, „Interpreting”, 9(2), s. 137-176.

Chmiel A., Mazur I., 2013, Eye tracking sight translation performed by trainee interpreters, [w:] Tracks and Treks in Translation Studies. Selected papers from the EST Congress, Leuven 2010, C. Way, S. Vandepitte, R. Meylaerts, M. Bartłomiejczyk (red.), Amsterdam-Philadelphia, s. 189-205.

Cohen A. D., Hosenfeld C., 1981, Some Uses of Mentalistic Data in Second Language Research, „Language Learning”, 31(2), s. 285-313.

Díaz Galaz S., 2018, A stimulated recall study on comprehension strategies for interpreting: implications for interpreter training, referat wygłoszony na konferencji didTRAD PACTE, Barcelona 20-23 czerwca 2018 roku.

Dybiec-Gajer J., 2013, Zmierzyć przekład? Z metodologii oceniania w dydaktyce przekładu pisemnego, Kraków.

Englund Dimitrova B., 2005, Expertise and Explicitation in the Translation Process, Amsterdam-Philadelphia. 
Englund Dimitrova B., Tiselius E., 2009, Exploring retrospection as a research method for studying the translation process and the interpreting process, [w:] Methodology, Technology and Innovation in Translation Process Research, I.M. Mees, F. Alves i S. Göpferich (red.), Copenhagen, s. 109-134.

Englund Dimitrova B., Tiselius E., 2014, Retrospection in interpreting and translation: Explaining the process?, „Monti”. Special Issue - Minding Translation 1, s. 177-200.

Ericsson K. A., Simon H. A., 1980, Verbal reports as data, „Psychological Review", 87(3), s. 215-251.

Ericsson K. A., Simon H. A., 1984, Protocol Analysis: Verbal Reports as Data, Cambridge, MA.

Ferreira A., 2014, Analyzing recursiveness patterns and retrospective protocols of professional translators in L1 and L2 translation tasks, „Translation and Interpreting Studies", 9(1), s. 109-127.

Gile D., 1998, Observational studies and experimental studies in the investigation of conference interpreting, „Target”, 10(1), s. 69-93.

Gile D., 2004, Integrated problem and decision reporting as a translator training tool, „The Journal of Specialised Translation”, 2, s. 2-20.

Gumul E., 2006, Explicitation in simultaneous interpreting: A strategy or a by-product of language mediation?, „Across Languages and Cultures”, 7(2), s. 171-190.

Gumul E., 2008, Explicitation in simultaneous interpreting - The quest for optimal relevance?, [w:] Relevant Worlds: Current Perspectives on Language, Translation and Relevance Theory, E. Wałaszewska, M. Kisielewska-Krysiuk, A. Korzeniowska i M. Grzegorzewska (red.), Cambridge, s. 188-205.

Gumul E., 2010, Błąd w retrospekcji, czyli czego możemy się dowiedzieć $\mathrm{z}$ uwag retrospektywnych tłumaczy symultanicznych, [w:] Błąd (i jego konsekwencje) w przekładzie, P. Fast, A. Świeściak (red.), Katowice, s. 277-302.

Gumul E., 2012, Tłumacz o ograniczeniach. Z uwag retrospektywnych tłumaczy symultanicznych, [w:] Z zagadnień dydaktyki tłumaczenia ustnego 2. Stare problemy, nowe metody, P. Janikowski (red.), Częstochowa, s. 91-116.

Gumul E., 2017a, Explicitation in Simultaneous Interpreting. A Study into Explicitating Behaviour of Trainee Interpreters, Katowice.

Gumul E., 2017b, Explicitation and directionality in simultaneous interpreting, „Linguistica Silesiana”, 38, s. 311-329. 
Gumul E., 2018, Searching for evidence of Gile's Effort Models in retrospective protocols of trainee simultaneous interpreters, „Między oryginałem a przekładem", 24(42), s. 17-39.

Hansen G., 2005, Experience and emotion in empirical translation research with think-aloud and retrospection, „Meta”, 50(2), s. 511-521.

Hjort-Pedersen M., Faber D., 2010, Explicitation and Implicitation in Legal Translation - A Process Study of Trainee Translators, „Meta”, 55(2), s. $237-250$.

Hurtado Albir A., Beeby A., Fernández M., Fox O., Martínez Melis N., Neunzig W., Orozco M., Presas M., Rodríguez-Inés P., 2002, „Una investigación empírico-experimental sobre la adquisición de la competencia traductora", [w:] La traducción científico-técnica y la terminología en la sociedad de la información, A. Alcina Caudet, S. Gamero Pérez (red.), Castellón de la Plana, s. 125-138.

Hurtado Albir A., Alves F., Englund Dimitrova B., Lacruz I., 2015, A retrospective and prospective view of translation research from an empirical, experimental, and cognitive perspective: The TREC Network, „Translation \& Interpreting", 7(1), s. 5-25.

Hvelplund K. T., Dragsted B., 2018, Genre familiarity and translation processing: Differences and similarities between literary and LSP translators, [w:] Innovation and Expansion in Translation Process Research, I. Lacruz, R. Jääskeläinen (red.), Amsterdam-Philadelphia, s. 55-76.

Ivanova A., 1999, Discourse Processing During Simultaneous Interpreting: An Expertise Approach, niepublikowana praca doktorska, University of Cambridge.

Ivanova A., 2000, The use of retrospection in research on simultaneous interpreting, [w:] Tapping and Mapping the Processes of Translation and Interpreting: Outlooks on Empirical Research, S. Tirkkonen-Condit, R. Jääskeläinen (red.), Amsterdam-Philadelphia, s. 27-52.

Jääskeläinen R., Tirkkonen-Condit S., 1991, Automatised Processes in Professional vs. Nonprofessional Translation: A Think-aloud Protocol Study, [w:] Empirical Research in Translation and Intercultural Studies: Selected Papers of the TRANSIF Seminar, S. Tirkkonen-Condit (red.), Tübingen, s. 89-109.

Kościałkowska-Okońska E., 2013, Recenzja książki Translation and Cognition, red. Gregory M. Shreve, Erik Angelone, Amsterdam-Philadelphia: John Benjamins, American Translators Association Scholarly Monograph Series XV, „Rocznik Przekładoznawczy. Studia nad teorią, dydaktyką i praktyką przekładu”, 5, s. 241-245.

Kubiak P., 2009, Fundamenty dydaktyki przekładu zorientowanej na proces, 
„Rocznik Przekładoznawczy. Studia nad teorią, dydaktyką i praktyką przekładu", 8, s. 257-265.

Muñoz Martín R., 2014a, Una instantánea movida de la investigación en procesos de traducción, „Monti”. Special Issue - Minding Translation 1, s. $9-47$.

Muñoz Martín R., 2014b, A blurred snapshot of advances in translation process research, „Monti”. Special Issue - Minding Translation 1, s. 49-84.

Napier J., 2002, Sign Language Interpreting: Linguistic Coping Strategies, Coleford, UK.

Napier J., 2004, Interpreting omissions: A new perspective, „Interpreting”, 6(2), s. 117-142.

Ng B. C., Obana Y., 1991, The use of introspection in the study of problems related to interpretation from Japanese into English, „Meta”, 36(2/3), s. 367-381.

O'Brien S., 2007, Pauses as indicators of cognitive effort in post-editing machine translation output, „Across Languages and Cultures”, 7(1), s. 1$-21$.

O'Brien S., 2008, Processing fuzzy matches in translation memory tools: An eye-tracking analysis, [w:] Looking at Eyes: Eye-Tracking Studies of Reading and Translation Processing, S. Göpferich, A. L. Jakobsen i I. Mees (red.), Frederiksberg, s. 79-102.

Olszewska J., 2007, Wiedza i wyobraźnia a zjawisko fałszywej pamięci, „Roczniki Psychologiczne", 10(2), s. 75-88.

Piotrowska M., 2000, Protokoły głośnego myślenia - TAPs, [w:] Mała encyklopedia przekładoznawstwa, U. Dąbska-Prokop (red.), Częstochowa, s. $163-166$.

Piotrowska M., 2002, A Compensational Model for the Strategy and Techniques in Teaching Translation, Kraków.

Piotrowska M., 2006, Protokoły głośnego myślenia - analiza świadomości tłumacza, [w:] Z problemów przekładu i stosunków międzyjęzykowych, Kraków, s. 101-107.

Piotrowska M., 2007, Proces decyzyjny tłumacza, Kraków.

Płużyczka M., 2013, Okulograficzne spojrzenie na trudności translacyjne, „Rocznik Przekładoznawczy. Studia nad teorią, dydaktyką i praktyką przekładu", 8, s. 59-76.

Płużyczka M., 2015, Tłumaczenie a vista. Rozważania teoretyczne i badania eye-trackingowe, Warszawa.

Rodríguez-Inéz P., 2017, Corpus-Based Insights into Cognition, [w:] The Handbook of Translation and Cognition, J. W. Schwieter, A. Ferreira (red.), Hoboken, NJ, s. 265-289. 
Saldanha G., O’Brien S., 2013, Research Methodologies in Translation Studies, London - New York.

Shamy M., de Pedro Ricoy R., 2017, Retrospective protocols: Tapping into the minds of interpreting trainees, „Translation \& Interpreting”, 9(1), s. $51-71$.

Shreve G. M., Angelone E., Lacruz I., 2014, Efficacy of screen recording in the other-revision of translations: Episodic memory and event models, „Monti”. Special Issue - Minding Translation, 1, s. 225-245.

Tang F., 2018, Explicitation in Consecutive Interpreting, Amsterdam-Philadelphia.

Tirkkonen-Condit S., 1992, The interaction of world knowledge and linguistic knowledge in the processes of translation. A think-aloud protocol study, [w:] Translation and Meaning 2, B. Lewandowska-Tomaszczyk, M. Thelen (red.), Maastricht, s. 433-440.

Toury G., 1995, Descriptive Translation Studies and Beyond, Amsterdam.

Vik-Tuovinen G.-V., 2002, Retrospection as a method of studying the process of simultaneous interpreting, [w:] Interpreting in the 21st Century: Challenges and Opportunities, G. Garzone, M. Viezzi (red.), Amsterdam-Philadelphia, s. 63-71.

Whyatt B., Stachowiak K. i Kajzer-Wietrzny M., 2016, Similar and different: cognitive rhythm and effort in translation and paraphrasing, „Poznań Studies in Contemporary Linguistic", 52(2), s. 175-208.

Witkowska M., 2010, Zastosowanie protokołu głośnego myślenia i retrospekcji w badaniach autorefleksji przyszłych nauczycieli języka angielskiego, „Neofilolog", 34, s. 147-157.

\section{On the method of retrospective protocols in simultaneous interpreting research Summary}

The aim of this paper is to discuss the method of retrospective protocols in simultaneous interpreting research. The author characterises the method in the context of other process methods and presents various retrospective procedures adopted so far in the studies conducted in the field of conference interpreting. The paper also aims to discuss the limitations of the method and possible solutions to overcome the inherent constraints. The exemplification presented in the article comes from the author's own research.

Keywords: simultaneous interpreting, retrospective protocols, research methods, process research

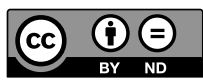

